\title{
PARA UNA AESTHESIS DESCOLONIAL DESDE EL PARADIGMA DE LA LIBERACIÓN EN LAS OBRAS DE ENRIQUE DUSSEL Y RODOLFO KUSCH
}

\author{
CHRISTIAN SOAZO AHUMADA ${ }^{1}$
}

\begin{abstract}
RESUMEN: El presente trabajo propone los fundamentos de una aesthesis descolonial desde el marco categorial provisto por la "exterioridad crítica" (Dussel) y el "estar-siendo" (Kusch) americanos frente al orden dominante de la totalidad moderno-occidental. Desde un universo de sensibilidad/afectividad configurado por la racionalidad vida-muerte (reproductiva) se plantea la importancia de la reproducción de la corporalidad viviente desde el campo económico y ritual/cultual para la generación del sentido cultural comunitario. A partir de este horizonte hermenéutico se comprende la significación de una nueva estética americana, obediencial, fundamentada desde las fuerzas vitales, mesiánicas, del espacio comunitario, con el fin de transformar la praxis social en un espacio de sensibilidad (aesthesis descolonial) orientado hacia una nueva constelación política de liberación.
\end{abstract}

PALABRAS CLAVE: aesthesis; comunidad; descolonización; liberación; política.

Abstract: This article proposes the foundations of a decolonial aesthesis from the categorical framework provided by the critical exteriority (Dussel) and the American "estar-siendo" (Kusch) against the dominant order of the modern-western totality. From a universe of sensitivity/affectivity configured by life-death rationality (reproductive), it is considered here the importance for the generation of the cultural sense of the reproduction of living corporality from the economic and ritual/cultual field. Only from this hermeneutic horizon, it is understood the significance of a new American aesthetic (obediencial), based on the vital, messianic, forces of the community space, in order to transform social praxis into a space of sensitivity (decolonial aesthesis) oriented towards a New constellation political of liberation.

KEYWORDS: aisthesis; community; decolonization; liberation; politic

\section{Horizonte estético occidental e indígena-popular en América Latina}

La estética hegemónica impuesta en América es para Dussel una estética eurocéntrica, colonialista y esteticida. Se crea según el fetichismo de la totalidad estética configurado a partir de la centralidad labrada por Europa desde 1492, en lo que se denomina "modernidad" (2018, 24). Esta centralidad "producirá inevitablemente la negación del valor de todas las Otras

\footnotetext{
${ }^{1}$ Investigador asociado del Centro de Investigaciones Estéticas Latinoamericanas (CIELA), Facultad de artes, Universidad de Chile. Doctor en filología románica, Universidad de Freiburg, Alemania. Email: christiansoazo@yahoo.es.
} 
estéticas (...) como un aspecto central de la instalación de la bipolaridad que comienza a formarse en el Caribe de la modernidad/colonialidad" (24). Esta realidad de facto, violenta y genocida, se emplazó sobre la división bipolar entre ser (sujetos almados) y no-ser (sujetos desalmados), entre superioridad e inferioridad ontológicas. Se impuso con la conquista por sobre una aesthesis comunitaria, centrada en la dinámica orgánica del valor de uso y de las experiencias populares ligadas a la corporalidad viviente (5). En el caso del pensamiento de Kusch, el "fetichismo de la totalidad estética moderna" encuentra su correlato en la noción de canon occidental. Su imposición colonial se asienta en las clases medias occidentalizadas que materializan el cuerpo de "lo social", conllevando, sin embargo, que "lo realmente vital se halla por debajo de lo social, por una suerte de proceso de amparo que asume el grupo social medio, subvirtiendo lo vital a las formas logradas o adquiridas" (2000a, 780). Lo que aquí está en juego, como lo expone Kusch, es "un simple canon que subsume a la verdadera vida" (780). Por tanto, lo occidental, su dimensión colonialista y esteticida, se apoya últimamente en "formas logradas o adquiridas", que no son más que un "canon que subsume a la vida verdadera", o sea, al referente fundamental de una aesthesis descolonial o afectividad comunitaria como es la vida real y material, expresada ya sea a nivel de la cultura popular, del sistema de prestación andino (ayni) o de la experiencia del estar americano.

A partir de aquí, Dussel concibe el esteticidio relacionado directamente con el genocidio y encubrimiento del otro, induciendo a que: "Los otros mundos culturales de Europa serán juzgados como primitivos, bárbaros, sin belleza alguna, en el mejor de los casos folklóricos" $(2018,24)$. El correlato de lo que pudiera concebirse por "esteticidio" se halla en la obra de Kusch en la imagen del indio/muerto configurada desde el "descubrimiento" del otro. Es lo muerto lo indígena sólo por la colonialista objetividad científica que concibe a "lo indio como objeto, (pues) dentro del espacio vacío del mundo occidental es la nada" (2000a, 786). Aquí el esteticidio toma claramente la forma de la nulificación ontológica desarrollada por Fanon en torno a la experiencia vivida del negro ${ }^{2}$. En el caso del mundo indígena, éste no dispone de legitimidad porque no tiene utilidad para una realidad como la occidental, conformada a espejo del fetichismo utilitarista del mercado. De aquí que, para el marco categorial del mundo occidental, lo indio "no tiene ninguna validez política, social o artística, es decir que no entra vitalmente a formar parte de dicho ámbito. En este sentido, lo indio es estrictamente lo muerto y por tanto se relega al museo como algo monstruoso y aberrado" (2000a, 786). No entrar vitalmente significa simplemente desaparecer, ser "encubierto", como sostiene Dussel, a través

\footnotetext{
${ }^{2}$ Como lo expresa en la noción nula resistencia ontológica. Cf. Fanon (2009), Soazo (2018).
} 
del proceso de occidentalización/colonización padecido por América, implicando, no obstante, una constante tensión y agonía entre la desaparición genocida del indio (condición óntica) y la supervivencia político-epistémica de lo indígena (horizonte transontológico o ético).

Dussel establece que la estética moderna, enquistada en la médula de las prácticas esteticidas occidentales, no es más que la parte "limpia" de la poiesis humana (Dussel, 1984, 64), ocultando con este enmarcamiento las zonas oscuras del no-ser, tanto de los trabajadores explotados como de los excluidos del sistema. Así, la estética será "la parte limpia de la producción, la de las clases dominantes, de los genios, dejando en el mundo oscuro de lo irracional, despreciable, molesto, económico, al trabajo asalariado del obrero del capitalismo" (Dussel, 2015a, 234). Este "mundo oscuro de lo irracional" es el sustrato de la noción de lo tenebroso desarrollada por Kusch, de acuerdo con su imaginería del arte americano, basada en la intención de fijación y contención, mediante la disposición artística, de una vida postergada frente a lo social (2000a, 783). Asimismo, la parte "limpia" de la producción encarnada en la estética moderna se consuma dentro del gran horizonte de sentido de la cultura occidental, cristalizado, según Kusch, en la idea de pulcritud. Esta noción va claramente aparejada con la de blanquitud expuesta por Echeverría, conforme a un comportamiento ético-económico (ethos) ligado con el capitalismo protestante $(2010$, 58). Kusch argumenta que este ethos de "pulcritud/blanquitud” capitalista se apoya "en las clases medias en gestación, con su actitud intelectual frente al mundo, traducida en Reforma, y que llegó a contaminar al catolicismo" (2000b, 123). Esta actitud intelectual intenta encubrir una pulsión vital, un miedo ontológico ante el "desgarramiento del cosmos", ligado fundamentalmente con el simple hecho de vivir (Kusch, 2000c, 320). Esto es lo que se pone en tela de juicio en una episteme como la modernooccidental, donde se conjugan irresolublemente tanto la "pulcritud" de una razón aséptica intelectual como la necropolítica u horizonte concreto de muerte y violencia territorial. El asunto es que las consecuencias políticas dependerán de la posición asignada en la cartografía global de poder, según la marcatoria colonial de los cuerpos, siendo el contexto necropolítico de vastas zonas de Latinoamérica y el Sur Global, el lugar donde radican los "sujetos" que son racializados como vida postergada o zona oscura del no-ser (Fanon, 2009).

Lo que se designa como "estética" en América alcanza su rasgo distintivo en la noción de escisión. El arte realizado en el mundo colonial se encuentra radicalmente dividido, según Dussel, entre un arte de elite y un arte popular. Este último, sin embargo, pareciera existir en el "vacío absoluto" de la estética colonial, por situarse "fuera" del espacio-tiempo creativo (y disciplinario) de la estética moderna. En este sentido, toda obra estética no-moderna "desde el 
Tawantinsuyu andino hasta la China de los Ming es objeto de un juicio esteticida, una necroestética que deja en la exterioridad del no-ser, en la exclusión de considerarlas como obras estéticas de los pueblos de todas las culturas coloniales" (Dussel, 2018, 26). En el caso del pensamiento de Kusch, la escisión de la "estética" se materializa entre un patrón civilizatorio occidental, desde donde la elite latinoamericana ejerce el poder de dominación colonial y un esquema indígena-popular, desde donde afirman su cultura las tradiciones ancestrales de la América profunda (Kusch, 2000b). El "vacío absoluto" de las prácticas estéticas coloniales, especialmente indígenas, llega a ser metaforizado por Kusch como abismático. En torno a este escenario hermenéutico se comprende su idea del arte americano en tanto "dual, bifronte con dos caras, que mantienen entre sí un abismo similar a la oposición entre Dios y el Diablo" (2000a, 779). Aquí, ciertamente la separación insalvable, la marcatoria radical de los cuerpos, es la colonialidad misma. Esta es la impronta formativa del espacio colonial y desde donde una aesthesis descolonial inevitablemente, y como máxima apelación de liberación, debe apuntar en el camino de descolonizar/liberar el horizonte de comprensión y la disposición aesthesicoafectiva del mundo indígena-popular del marco categorial y supuestamente "omnisensible" del pensamiento abismal moderno-occidental (Santos, 2013).

\section{Categorías de Exterioridad y Estar para una aesthesis descolonial}

En la obra de Dussel la categoría de exterioridad ${ }^{3}$ (2011, 41) asume fuertes implicaciones con la estética, especialmente con su dimensión aesthesica. En primer término, la aesthesis es la disposición fenomenológica primera, en tanto apertura de la subjetividad humana a los hechos originarios de la realidad cosmológica (Dussel, 2018, 2). Desde este nivel de radicalidad y enraizamiento emerge la noción de belleza ligada con la apertura fenomenológica desde las cosas reales ${ }^{4}$ que pretenden "ser" en el mundo (potencialmente en cualquier "mundo cultural"), primeramente, queriendo vivir en él. Como sostiene Dussel: "Se sitúa así el ser humano ante las cosas reales del mundo, los fenómenos, implicados por distintas maneras de afectar la subjetividad mundana del que vive dicho mundo. Esa presencia, afecta la subjetividad en su sensitividad-inteligente o en su inteligencia sensitiva, unitaria e inseparable"

\footnotetext{
${ }^{3}$ Remite a un ““"más allá” del horizonte del ser del sistema una trascendentalidad interior (...) trascendentalidad interior o exterioridad tienen la misma significación en este discurso filosófico" (Dussel, 2011, 77). Sobre la relación entre exterioridad y aesthesis descolonial apuntará el desarrollo de este apartado.

${ }^{4}$ Las nociones de realidad y cosmos comprenden un espacio de trascendencia insubsumible frente al "ser" del "mundo". En este sentido, Dussel expone que "hay realidad también más allá del ser, así como hay cosmos también más allá del mundo (...) más allá del ser, trascendiéndolo, hay todavía realidad. Si la realidad es el orden de constitución cósmica de las cosas, resistentes, subsistentes y crecientes de suyo desde sí, es evidente que hay más allá del ser" (2011, 78-79). Esta categoría de realidad se halla directamente relacionada con la noción de estar desarrollada por Kusch, como se intentará argumentar a lo largo de esta exposición.
} 
$(2018,3)$. En el pensamiento de Kusch, su concepción del "estar" americano establece vínculos intrínsecos con la estética, igualmente a partir de su dimensión aesthesica. La función de "mediación" que ocupa la categoría de belleza en Dussel, en relación con su apertura aesthesica desde la sensibilidad natural, vital, cosmológica, encuentra su análogo en la obra de Kusch en su concepción sobre lo fasto y lo nefasto (Kusch, 2000c, 279). Esta es igualmente la dimensión aesthesico-afectiva a partir de la cual la subjetividad viviente se abre al orden cosmológico, lo

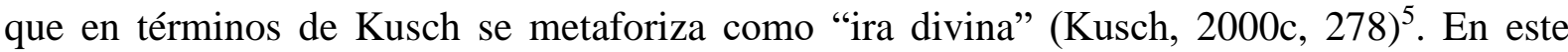
sentido, desde lo más profundo del horizonte cultural andino, se aprecia ya que los antiguos incas concebían a la realidad como si tuviera dos caras sometida al azar: a lo fasto y lo nefasto (2000d, 182). Esta cosmovisión centrada en torno a la dualidad no es una mera proyección lógica o discursiva, toda vez que su fuente de significación proviene de la vida misma. De aquí que lo esencial para el pensamiento indígena-popular no sea tanto el "qué" cognoscitivo del universo objetual, de la definición causalista-logocéntrica occidental, sino el "cómo" de los modos o aspectos de darse lo viviente, vinculados con el espacio de afectividad primario, o sea con "el predominio del sentir sobre el ver mismo de tal modo que ve para sentir, ya que es la emoción la que da la tónica a seguir frente a la realidad" (Kusch, 2000c, 280). Así, el sentir/emoción es fundamental para ver la mediación de las cosas - justamente el ámbito de la aesthesis definido por Dussel - en relación con lo fasto y nefasto, la vida y la muerte o el acontecimiento existencial en cuanto tal. Por tanto, si en Dussel la aesthesis expresa su dimensión cosmológica ligada con la belleza, conforme a la disposición de las propiedades físicas de las cosas reales manifestadas fenomenológicamente al ser subsumidas en el mundo (campo estético), siendo así un momento cósmico dentro de él $(2018,5)$, en el caso de Kusch, la aesthesis también se desprende desde un plano cosmológico, en el que lo vital, vinculado directamente con la percepción, se halla por debajo de la expresión formal/fenomenológica de lo social, quedando así subsumido lo vital de la realidad cosmológica en las "formas logradas o adquiridas" del canon occidental o "campo estético" (2000a, 780).

Si se toma como punto de partida el método analéctico propuesto por Dussel (1974), el enfoque categorial configurado es de orden trascendente a la lógica identidad/diferencia, corporizada por la línea abismal del pensamiento moderno-occidental (Santos, 2013), entre el ser y el no-ser (o seres humanos cuya humanidad está puesta en tela de juicio). Desde este mirador, más que la lógica identidad/diferencia, donde la identidad últimamente es occidente y

\footnotetext{
${ }^{5}$ La noción de "ira divina" en Kusch establece un estrecho vínculo conceptual con la de "realidad/naturaleza" presente en la obra de Dussel (cf. nota 3).
} 
la diferencia el resto de las culturas subalternas del planeta, se concibe un horizonte de semejanza, vinculado al espacio de experiencias comunes (por el simple hecho de convivir como especie en este planeta) y un universo de distinción referido a las particularidades fenomenológicas de cada cultura. De acuerdo con esta consideración, la aesthesis en su nivel más basal, vinculado con el ámbito de la "realidad/naturaleza", encarna en el pensamiento de Dussel la condición de semejanza analéctica. La distinción remite, por su parte, a las diversas configuraciones que adopta la aesthesis, dependiendo de las diversas pluralidades analógicas configuradas por el cruce del campo estético con otros universos de sentido $(2018,18)$. En el caso del sistema categorial kuscheano, ligado con el "gran arte", con el universo vital de lo biológico, de las fuerzas informes de la especie, se aprecia, en el mismo plano de la aesthesissemejanza dussealiana, la experiencia de lo tenebroso y del estar. Por tanto, la semejanza analéctica aquí es la experiencia subyacente de lo vital conceptuada como tenebrosa. Kusch sustenta una estética de lo americano no basada "en una estética del arte sino del acto artístico, precisamente porque éste incluye lo tenebroso cuando contempla ese proceso brumoso que va de la simple vivencia del artista a la obra como cosa" (2000a, 782). En este punto la "simple vivencia del artista" refiere a la aesthesis, es decir, a la subjetividad fenomenológica convocada en el proceso de apertura sensible, vital. Por tanto, la experiencia del devenir, del estar, o dimensión cosmológica de lo real, se relaciona directamente con la idea de acto artístico en Kusch - y su estrecha correlación con la aesthesis/semejanza dusseliana -, donde lo importante, más allá de las creaciones e instalaciones en el mundo, es el proceso vital comprometido en la praxis comunitaria. De igual modo, la distinción analéctica concierne aquí, en el espacio colonial americano, a la forma estructurada conforme a un canon comprensible, el cual se caracteriza por disponer de un contenido referido a lo vivo y una forma ligada a las normativas del canon, en tanto imágenes y sensibilidades de la burguesía eurocéntrica.

El punto cardinal aquí es que tanto la idea de exterioridad como de estar, mediante el despliegue de la sensibilidad originaria o aesthesis comunitaria, ya sea descolonizando la concepción de belleza occidental, llevada a cabo por Dussel, o proponiendo un marco categorial como el andino, en el caso de Kusch, se fundamentan desde la sensibilidad vida/muerte. Para Dussel la estética de la liberación es la comprensión de toda la estética desde el criterio vidamuerte, donde la belleza es la expresión de la vida y la fealdad la de la muerte $(2018,7)$. En el pensamiento de Kusch, como se indicó, la dimensión aesthesico-afectiva igualmente se constituye desde la condición vida-muerte, en la conjuración del advenimiento del maíz o la maleza (Kusch, 2000b, 66), encarnada en las experiencias de lo fasto y lo nefasto, donde lo 
fasto corresponde a la vida y lo nefasto a la muerte. Desde el universo categorial provisto por el mundo indígena-popular, se concibe que más que las cosas en sí mismas lo que importa es su uso. Por tanto, lo significativo y originario de la vinculación con las "cosas reales" es el hecho de que éstas sean mediaciones para la vida, disponiendo en última instancia de un uso fasto o nefasto de los entes del mundo.

Dussel observa la importancia de la noción de presencia, ligada con la patencia de la experiencia originaria llamada estética $(2018$, 8), en la conjunción entre belleza y aesthesis. Desde este espacio germinal emergen las propiedades físico-cósmicas en tanto fundamento material de la experiencia aesthesica. De aquí que conciba la aesthesis como "un modo de presencia de la cosa real ligada a la posibilidad del sujeto de seguir viviendo plenamente" (2018, 6). La belleza se constituye en la disponibilidad de la cosa real como mediación para la realización de la vida. Asimismo, en la obra de Kusch la dimensión aesthesico-afectiva comprendida en la cosmogonía de lo fasto/nefasto encuentra en el ejercicio de la presencia, especialmente en el universo pragmático del rito/culto, una significación referencial arquetípica desde donde erigir el horizonte simbólico del ethos indígena. El sentido real del rito es "la determinación gestual, pasajera, donde se confirma un fundamento que se ubica en lo dado, que el campesino con-sagra, o sea con lo cual se pone en paralelo con lo sagrado" (2000e, 326). Desde "lo dado" entonces, desde lo que se vincula con la experiencia del estar, se apela a que la presencia sagrada se trueque de nefasta en fasta. El concepto de estar debe pensarse entonces como "algo anterior a ser y que tiene como significación profunda el acontecer" (Kusch, 2000f, 227). Se asocia al vivir en la medida en que éste se vincula al "vivir sin más que se rodea de cultura, entendida ésta como universo simbólico y que sirve para encontrar el amparo. Por eso es ético y no gnoseológico. Dice dónde se hace lo fasto y se evita lo nefasto, pero no dice qué es un objeto" (227). Así, el objeto puede ser algo cuantitativo y cualitativo, pero nunca algo sustancial, pues "vivir es estar firmemente aquí y eso se da al margen del objeto: en el terreno de la comunidad, el fruto y la presencia de la ira" (Kusch, 2000b, 210). Desde esta experiencia radical, se concibe al rito como aquella "puesta en juego" donde se ensaya la tangibilidad del presente y su permanente resignificación según el devenir de las circunstancias vitales y de los sujetos involucrados en ellas.

En el pensamiento de Dussel, la aesthesis ocupa el espacio ontológico de la estética, aunque más específicamente, siguiendo las premisas centrales de toda su obra, el horizonte 
transontológico o ético ${ }^{6}$. Las obras de arte, por su parte, despliegan el universo óntico. En este sentido expone: "Nos ocuparemos entonces de una estética que se compondrá del momento ontológico de la áisthesis y del momento óntico o expresivo-productivo de la obra de arte" $(2018$, 2). El momento trans-ontológico es el de la sensibilidad vida/muerte, la apertura arquetípica y raigal de la corporalidad viviente, desde dónde - lugar aesthesico o aesthethos se dan las condiciones sensibles para la vida o la muerte, para la afirmación de la vida comunitaria, por ejemplo, con las afecciones (feas/enfermas/opresivas/contaminadas) provocadas por la pobreza y la contaminación ecológica, en contraposición con las señales, tanto humanas como naturales, para sentir la afirmación plena de la vida afectiva (bellas/sanas/liberadoras/purificadas).

En la obra de Kusch, la dimensión ontológica del arte radica en la instalación del ente vital, del artista; de lo que Kusch denomina "gestor cultural" o "fórmula en la cual se encuadra el auténtico creador" (2000f, 179), esto es, la concepción genuina de un creador como "un gestor del sentido dentro de un horizonte simbólico local, en una dimensión que afecta a todos, o sea que es popular en tanto corresponde al requerimiento implícito de todos los "habitantes"" (180). En este punto Kusch converge, como veremos, con la noción de estética obediencial de Dussel, en el sentido de una estética emergida desde abajo, desde el pueblo. Por tanto, se sitúa en contraposición a la estética occidental propensa a valorizar más el producto artístico u objeto estético (la relación proxémica, sujeto-objeto) que la génesis de ese producto (relación de proximidad, sujeto-sujeto o sujeto colectivo), o sea, se legitima más la obra que el artista (2000a, 781), especialmente si éste se piensa como constituyente de una comunidad histórica. En este ámbito se es proclive a la fetichización de lo visible y lo formal, esto es, la obra de arte por sobre lo invisibilizado o encubierto, a saber, la creación de ese producto, o sea, el artista, en una clara analogía al "obrero" o "trabajador” inserto en una clase proletaria y en una tradición comunitaria, siendo así la obra de arte el producto, es decir, el análogo de la mercancía.

Se puede concluir este apartado, enfatizando el nexo de la aesthesis con las categorías de exterioridad en Dussel y estar en Kusch. En efecto, una aesthesis descolonial/liberación se lleva a cabo necesariamente desde el paso o mediación dada de la realidad/exterioridad al mundo/ser (Dussel), como del "estar nomás" al "ser alguien" bajo la figura del estar-siendo (Kusch).

\footnotetext{
${ }^{6}$ Es trans-ontológico o ético, pues se vincula con la subjetividad viviente - el artista - posibilitante de cualquier marco categorial para la vida, es decir, la aesthesis se consustancia a la ética o lo transontológico.
} 


\section{Economía y rito para una aesthesis descolonial}

En la obra de Dussel, la aesthesis expone una dinámica semejante a la del valor de uso. Se relaciona con el "ciclo vital primigenio", ligado con el espacio referencial arquetípico proveniente de la "realidad/naturaleza", a través de la dimensión "inteligida/sensible" de la experiencia de la belleza. Se establece una clara analogía entonces entre aesthesis y valor de uso, pues como menciona Dussel: "el valor de uso de una cosa real se constituye desde la necesidad del viviente, a partir de las propiedades físicas que se manifiestan como útiles para la vida" (2018, 4). En este sentido, Dussel agrega, en el mismo horizonte categorial de la aesthesis, que "la cosa real es ahora una mediación para la vida. El valor de uso tiene una referencia a la cosa física como portadora material de un valor de uso constituido como mediación desde la necesidad de la subjetividad humana como corporalidad viviente" (4-5). Sin subjetividad viviente no hay valor de uso, pero también sin la propiedad física real que lo sostenga; el valor de uso es entonces la cualidad real que porta la cosa, transformada en el contenido de la necesidad, por tanto, resulta ser la utilidad de la cosa (Dussel, 2014a, 21). En efecto, el valor de uso es útil en tanto mediación actual para reproducir la vida (21). Por tanto, decir "valor de uso" implica la misma esfera de sentido que decir "vida". Sin necesidades las cosas meramente existen, pero no tienen valor de uso. Éste remite entonces a las propiedades físicas de la materia y a la energía disponible para la vida (22). Esta mediación de "energía disponible" para la vida es precisamente la acepción que cobra la noción de aesthesis desde el prisma categorial dusseliano.

De acuerdo con el horizonte antropológico-cultural kuscheano, la aesthesis, en relación con el ámbito económico, se arraiga desde el sistema de prestación andino (ayni) con el "ciclo vital primigenio". Desde este topos o lugar aesthesico se instala igualmente la dominancia del orden referencial del mundo, su vinculación afectiva arquetípica, ligada seminalmente - en el eje de lo fasto y lo nefasto - con el orden cosmológico, la dimensión de "realidad/naturaleza" del mundo. El marco categorial asociado a la prestación, constituyente de la institución del ayni, se concibe como "un conjunto de 'favores' mutuos en vida, tomando como modelo el patrón de reciprocidad existente a nivel hatha o de la aldea" (Kusch, 2000c, 422). La simple energía de la comunidad, ligada con la dinámica orgánica de los valores de uso implicados en la reproducción social comunitaria, se vincula directamente con el patrón de reciprocidad existente en ella. En este sentido, la comunidad sobre la que se desarrolla la prestación "era entendida, ya no en términos contractuales o estadísticos como suma de individuos, sino estrictamente como organismo viviente, un hábitat donde fructificaba la actividad del hombre 
y todo lo viviente" (422). Así, el valor de uso de la reproducción social de la vida comunitaria indígena se afirma como experiencia aesthesica prístina, según la dinámica de la reciprocidad y la constitución orgánica del mundo.

En el sistema categorial dusseliano, relacionado con la estética de la liberación, el paso de la aesthesis a la poiesis cobra una importancia decisiva, ya sea desde el horizonte de la producción en general (Dussel, 1984) como desde el ámbito de las obras de arte (Dussel, 2018). En el campo de la producción en general, la vinculación con el oikos, con el universo económico, es determinante. En la articulación entre aesthesis y poiesis converge la dimensión económica con el espacio del rito. Dussel expone como ejemplo, desde el núcleo ético-mítico semita, el rito de la eucaristía cristiana. Se problematiza su dimensión económica toda vez que ésta posibilita una relación sacramental, por estar basalmente relacionada con la afirmación de la vida comunitaria (el oikos): "que no es puramente práctica, sino que incluye las exigencias objetivas de la mediación cósmica, material, cultural; es decir, toda la realidad empírica en su conjunto" (2015b, 343). Existe aquí una exigencia material, una dimensión objetiva proveniente de los requerimientos biológicos de la especie. Desde este horizonte de sentido se comprende el rito como "relación práctica mediada por momentos productivos, poiéticos, "fruto del trabajo y de la tierra"” (345). Lo que está detrás del pan en el rito eucarístico es "realidad y símbolo del producto-satisfactor (...) El pan es producto del trabajo (...) Es una relación técnicoproductiva" (345). El fundamento inaugural de esta concepción del pan revela que la estructura económica de la eucaristía concierne igualmente a "la rectitud de la objetividad y realidad de los efectos sistémicos empíricos de las acciones humanas (...) Esa objetividad realista crítica es la esencia de la sacramentalidad que involucra una estructura económica (analógica)" (348).

En el caso del pensamiento de Kusch, la dimensión de creación/poiesis se encuentra vinculada con el orden cosmológico primigenio en la medida en que lo arquetípico es la experiencia del estar, la referencia sagrada de lo meramente existente, expuesta en cada coyuntura a la variabilidad del acontecer, esto es, la circunstancialidad que rodea la vida y la muerte. Kusch ejemplifica, con el ciclo del pan vinculado con el núcleo ético-mítico amerindio, el íntimo maridaje entre economía y rito. Lo que aquí está en juego es la ejemplificación y simbolización desde lo más esencial del ethos indígena, o sea, desde la valoración de la dignidad de lo viviente y de la sacralidad del pacha. La "objetividad" de lo simple y fundamental es el desenvolvimiento de las raíces antropológicas del estar americano. El "ciclo del pan”, bajo este marco categorial, tiene lazos constituyentes con el estar. Aquél se manifiesta en cualquier lugar, estando, por ejemplo, en "la plaza, sumergidos en el mero estar" (Kusch, 2000b, 212). En estos 
espacios, cuasi puntos de fuga en la cronotopía del mundo occidental, pareciese no tener mayor importancia la creciente ficción de la ciudad: "no vale la pena tanta mentira para confesar esa pequeña verdad de nuestro pequeño y humilde ciclo del pan que no nos animamos a vivir" (213). El "ciclo del pan" remite en primer término a la mera reproducción social de la vida humana en todo el espectro de su realización simbólico-material, es decir, desde la alimentación básica para la sobrevivencia hasta el refinamiento espiritual en torno a los sentidos profundos de cada cultura. En una posición colonialista frente a aquél se emplaza el "ciclo del mercader", del ser hegemónico occidental, fundado sobre el principio de "ser alguien", el cual sólo frustra el "pequeño ciclo del pan, el amor y la paz" (213). Bajo este horizonte de sentido, se piensa la indigencia de no comer como una indigencia menor ante la mayor que es estar existiendo. De aquí que para Kusch "el problema no es el de comer, sino el de recobrar la dignidad del comer" (2000f, 176). En este sentido, la dignidad "se enreda en la ética de una cultura" (176), ligada con la radicalidad del estar, con la referencialidad sagrada de lo meramente dado, con la posibilidad de "pan, amor y paz", esto es, los medios constituyentes de afirmación de la vida comunitaria.

Según Dussel, el oikos adopta una significación referencial en las nociones de don y gratuidad, vinculada con la dimensión ritual. En efecto, los aztecas nombraban "al ser humano el deudor (macehual). Deudor ante los dioses por el don gratuito de la vida" (2014a, 35). En el núcleo ético-mítico de todas las culturas amerindias se venera a la madre por el mismo motivo, pues "es la donadora gratuita de la vida; donación absoluta que no puede pagarse nunca, porque el hijo no puede donar nunca la vida a la madre como retribución" (35). Para Dussel, el don es anterior a la justicia, toda vez que ésta sea comprendida como el tránsito desde un "estado del mundo", es decir, una referencialidad "objetiva" de la realidad concreta y material del mundo, una dimensión ética normativa desde la afirmación de la vida comunitaria hasta una mediación institucional o normativa político-jurídica (Dussel, 2014b). Así, el don es lo común por antonomasia, lo semejante intercultural, lo vinculado radicalmente con la proximidad, con la reciprocidad y con lo gratuito (Dussel, 2011). En este sentido, el don es anterior a la justicia porque no reclama pago alguno, ya que

la justicia es dar a cada uno lo que se merece. El don da al Otro algo antes que pueda merecer, o aun lo que no merece. Lo gratis, anterior a toda compra y venta económica, es su horizonte esencial, fundamental. Porque la gratuidad es la esencia del don: entregar algo sin esperar retribución. Es la economía perfecta, originaria y utópica por excelencia (Dussel, 2014a, 35-36).

La dimensión ritual, presente tanto en la eucaristía cristiana como en los cultos de los pueblos indígenas, parte del fundamento cosmológico material ligado basalmente con la 
categoría de proximidad histórica (Dussel, 2011), esto es, reciprocidad elemental entre madre e hijo y su extensión proyectiva en el seno de la comunidad. Esta proximidad originaria es la que orienta la praxis humana, o sea, la relación inmediata entre sujetos tiene como horizonte constitutivo la categoría de proximidad. Sin embargo, en esta relación práxica fundamental, desde donde las prácticas rituales extraen toda su fuerza performativa, se evidencia la expresión de una (in)mediación económica arquetípica, asociada con la "economía perfecta, originaria y utópica”, fuera del sistema de compra-venta económico y exterior al ordenamiento contractual del mercado capitalista. De aquí que lo fundamental para Dussel sea partir del don, del servicio, puesto que esto implica "la acción productiva de un miembro de la comunidad que no puede menos que participar en ella porque lo debe todo (...), y porque tiene conciencia plena de que la sobrevivencia de cada miembro es fruto de la mutua responsabilidad compartida" (2014a, 37). En este punto más que el enriquecimiento y la acumulación personales sostenidos por el ethos burgués, actúa la lógica de la presencia, de la participación y pertenencia, configurada a partir del reforzamiento de las relaciones de alteridad/responsabilidad comunitarias.

La dimensión económica u oikos en la obra de Kusch, establecida en el sistema de amparo o prestación andino (ayni), dispone como fundamento arquitectónico, la reciprocidad de una mirada orgánica del mundo, ligada con los funcionamientos naturales de la praxis vital comunitaria, de lo que se denomina habitualmente "cultura". En contraposición con la cultura del mercado capitalista (o del desamparo), de la "fiesta del mundo" o del "patio de los objetos", el horizonte andino concibe la noción de ayuno. Efectivamente, la vivencia religiosa aimara cobra toda su experiencia espiritual desde el "refugio del quichua en sasiy o ayuno frente a la fiesta del mundo" (Kusch, 2000b, 111). A contrapelo de la cultura moderno-occidental que incide sobre el mundo, modificándolo hasta su más perversa alienación, por su adicción a la acción y a los objetos, se arraiga un horizonte cultural como el andino, donde el "estar aquí" se vincula con la distensión, mientras el "ser alguien" occidental con la tensión. En este sentido: "El estar aquí es previo al ser alguien porque supone un estado de recolección, de crecimiento o acumulación y, por lo tanto, de privación y de ayuno de objetos y de elementos" (201). Este “estado de recolección y acumulación” se relaciona con la fase orgánica/holística del repliegue en la interioridad, esto es, en el mundo de la mesura, de la sobriedad, del equilibrio ecológico, vinculado estrechamente con el ayuno del mundo. Así, mientras el ayuno se relaciona con el don y la gratuidad, la "fiesta del mundo" lo hace con la "acumulación capitalista", en el escenario del "patio de los objetos" de la cultura moderno-occidental. En este ámbito se da el despunte de una verdadera acumulación enajenada, determinada por el fetichismo del mundo 
de las mercancías. Por tanto, el ayuno del horizonte indígena atañe básicamente a la experiencia del don y la gratuidad, desarrollada por Dussel, y al universo transontológico del "estar aquí" y del "ciclo del pan" expuesto por Kusch.

Si se quiere, para concluir este apartado, contrarrestar las posiciones de estos dos pensadores latinoamericanos, se puede decir que existe una distinción, únicamente conforme a la dominancia puesta en torno al paradigma de la liberación. En el caso de Dussel, se pone un mayor énfasis en la liberación desde la exterioridad a la totalidad dominante, esto es, desde la negación o exclusión de la cultura popular; expresión de la "negación de la negación" presupuesta por una praxis de liberación, asumiendo necesariamente un marco de afirmación previo, como es el "deseo de ser libre". En el pensamiento de Kusch, se advierte un realce en la liberación desde la negación, desde la lógica de la negación, o sea, una sui generis forma de "afirmación" de la cultura popular del pensamiento indígena-popular, acoplada seminalmente con la experiencia del estar, "exterior" a la lógica discursiva o apofántica del logos occidental, siendo expresión, más bien, de una especie de anti-discurso vinculado con la emocionalidad y la sobrevivencia (Kusch, 2000g, 571).

\section{Estética americana o estética obediencial: aesthesis descolonial para una política de la liberación}

Dussel concibe una estética obediencial trascendente a la estética kantiana del genio artístico, pues lo que predomina en este constructo es el horizonte categorial configurado por el individualismo metafísico moderno y la incomprensión de la historia mundial de la estética $(2018,21)$. Teniendo como panorama categorial un horizonte histórico más amplio que el del genio artístico y la autonomía estética moderna, la historia mundial de la estética siempre ha mostrado una dimensión comunitaria o estética del pueblo: "de las pequeñas y grandes culturas que son fruto comunitario de expresión de un tipo de belleza que surge del consenso de sus miembros durante centenas y hasta miles de años" (22). Bajo este horizonte de comprensión, lo que se conoce modernamente como "artista" tiene un marco referencial completamente distinto. La presencia del artista individual no es más que "el mejor y más coherente miembro en la comprensión y sensibilidad de la estética de la comunidad" (33). Sólo desde un horizonte transontológico ligado con la proximidad histórico-comunitaria de su biografía, se provee de sentido a su poiesis, en la medida en que es el mismo pueblo quien últimamente lo consagra, surgiendo así, a partir de una clara delegación comunitaria, el "genio artístico" singular, vinculado con la "expresión obediencial ante un pueblo, por llevar a la áisthesis y a la obra de arte comunitaria a su pleno desarrollo" (33). De este modo, se concibe, lo que podría designarse 
analécticamente como "genio" artístico, al que "nace desde el presupuesto de la estética comunitaria y es su consagración: es siempre la sede ontológica y el actor protagónico el pueblo mismo como potencia aesthesica" (33). Sería una expresión "analéctica", en la medida en que lo "semejante" es el fundamento aesthesico comunitario o el punto de partida de toda la experiencia estética popular, y la "distinción", la consagración propia del talento singular de cualquiera de los miembros de la comunidad. Una estética obediencial se instituye desde el consenso de la comunidad, en tanto "origen de la obra estética diseñada. El principio fundamental, normativo, ontológico y meta-físico, de una estética de la liberación es la estética obediencial" (Dussel, 2018, 21). La comunidad es la sede creativa de toda obra, es la potencia aesthesica. De aquí que "el artista obediencial debe interpretar el latido oculto de la belleza viviente de una comunidad histórica" $(2018,33)$.

La importancia de una estética popular en el pensamiento de Kusch proviene de la focalización en el proceso estético del artista, es decir, en su vivencia en tanto sujeto comunitario, dado que la creación estética supone "un proceso que parte del artista, como ente vital, y apunta hacia algo inmóvil, como lo es la obra" (2000h, 817). La idea de "ente vital" refiere a la condición de sujeto comunitario, ligado con el ámbito ontológico de la estética, a saber, el espacio de la sensibilidad afectiva, pues la mediación material que resulta ser la obra - esta dimensión "inmóvil” aludida por Kusch -, ya conlleva el universo óntico o de las particularidades fundadas y utilizadas desde el horizonte de la aesthesis comunitaria. Para Kusch el gran arte corresponde con la sobrevivencia, análogamente con la afirmación de la vida dusseliana $^{7}$. Lo que está en juego en este ámbito es una mirada especular, especialmente en referencia a la temática del mestizaje americano desarrollada por Kusch, en torno a la capacidad inquisitiva del mestizo de mirarse a sí mismo y cuestionarse colectivamente, en situaciones límites, sobre la dimensión raigal de la experiencia, sobre la circunstancialidad de todo ser (Kusch, 2000c, 527), en suma, sobre la coyuntura arquetípica en torno a la vida y la muerte. Bajo este contexto, Kusch afirma que "en todo gran arte el artista hace cuestionar al instinto colectivo su sobrevivencia" (2000a, 783), reflejando alrededor de la experiencia seminal del estar, lo auténtico del gran arte, esto es: "una respuesta plástica a la pregunta primordial que el grupo social - por intermedio del artista - se ha hecho sobre sí mismo" (783). Esta inquisición arquetípica, comunitaria, emergente desde abajo, desde las entrañas del "hedor" americano (Kusch, 2000b, 12), es intermediada por la gestión cultural del "artista”, en correlación con la

\footnotetext{
${ }^{7}$ E igualmente aquí, con la categoría de racionalidad vida/muerte o racionalidad reproductiva de Hinkelammert $(2017,205)$
} 
idea de poder y estética obedienciales de Dussel. Comprendiendo este horizonte categorial se entiende que la "crisis actual” (los 70' de Kusch) no sea realmente del pueblo, de los estratos profundos del horizonte simbólico-cultural del pueblo indígena, sino de los sectores medios, pues "estos se aferran al poder, y al hacer esto pierden el sentido de la convivencia. Es que la cuestión no radica en mandar, sino en escuchar al que recibe las órdenes" (Kusch, 2000g, 569). Aquí resuena claramente el nexo entre la importancia del escuchar en Kusch y el mandar obedeciendo en Dussel (2006). Para Kusch el problema de nuestro gran arte y de lo americano se evidencia en la escisión que revela por un lado el terreno de lo tenebrosamente vital, lo indígena y la tierra, y por el otro, lo formalmente evadido en las estructuras sociales de las ciudades (2000a, 785). En suma, "lo tenebrosamente vital, lo indígena y la tierra" son, siguiendo a Dussel para el caso de América Latina, la potencia aesthesica, el núcleo arquetípico del horizonte referencial indígena-popular.

Una estética obediencial, afín a una estética comunitaria o popular, emerge desde abajo, desde las zonas oscuras del no-ser, desde el "bloque histórico de los oprimidos" (Dussel, 2006, 54), teniendo como criterio arquitectónico la afirmación de la vida, el despliegue de la racionalidad vida/muerte, donde la belleza (Dussel)/fasto (Kusch) es a la vida como la fealdad (Dussel)/nefasto (Kusch) a la muerte. Sin embargo, en contextos altamente racializados y necropolitizados como los de América Latina, descendientes del genocidio y colonialismo americano tras 1492, lo feo es además lo vinculado con lo socialmente excluido o relegado, a través de siglos de colonialismo, capitalismo y patriarcado. Es lo nulificado, precarizado, llevado a un estado permanente de sobrevivencia. Igualmente es la producción de "negación" o de condición de "desecho" detrás de la categoría de Sur global ${ }^{8}$. Estas disposiciones radicales de exclusión y negación de las formas de ser y de sentir, desembocaron en la práctica marcatoria de los cuerpos, de las "entidades coloniales". Dussel sostiene claramente que "la piel negra africana y de otros colores dado el racismo marcatorio de la corporalidad queda inferiorizada o nulificada debido a la universalización de la superioridad occidental" $(2018,25)^{9}$. En el caso del pensamiento de Kusch, lo socialmente relegado y excluido, distintivo de una estética de lo americano, se relaciona con lo tenebroso generado por una vida postergada frente al orden social, cuya fijación y contención intenta ejercerse de algún modo (2000a, 783). Kusch comprende el "gran arte" como actualización de las cuestiones vitales retraducidas en "formas

\footnotetext{
${ }^{8}$ Santos lo desarrolla de acuerdo con la nulificación ontológica producida por el pensamiento abismal, en relación con "el ignorante (saber), el retrasado (tiempo), el local (espacio), el inferior (raza) y el improductivo (clase)" (Santos, 2013: 24).

${ }^{9}$ Nula resistencia ontológica desarrollada por el negro frente al blanco (Fanon, 2009; Soazo, 2018).
} 
o en signos comprensibles de aquello que socialmente fue excluido o relegado como algo tenebroso frente a la inteligencia social" (2000a, 783). Lo que está detrás de una estética de lo americano, vinculada con su dimensión popular-obediencial dussealiana, es la vida misma, es decir, el nivel primario de referencialidad de cualquier creación comunitaria. Como lo menciona Kusch: "lo más importante es la vida, incluso más aún, esa vida en su aspecto tenebroso. Si esto no existe, el arte se convierte en juego o en arte abstracto" (784). En este sentido, concibe, siguiendo la realidad argentina y americana, que el arte dominante es un arte oficial de tipo formalista, implicando con ello que lo gauchesco y el folklore queden reducidos, peyorativamente para este tipo de discurso, a "un arte de la vida o de lo tenebroso que se califica como popular" (804).

\section{Espacio cultural comunitario, mesianismo y nueva estética/política}

Un elemento crucial para comprender los alcances de la aesthesis comunitaria implicado en la situacionalidad espacial, en la condición raigal de la experiencia de la exterioridad, de la proximidad y del estar, es la idea de cultura. Para Dussel, ésta es una dimensión de nuestra existencia intersubjetiva e histórica, o sea: "un complejo de elementos que constituyen radicalmente nuestro mundo; ese mundo, que es un sistema concreto de significación" (2015a, 94). La radicalidad intersubjetiva e histórica se encarna en un espacio concreto, en un lugar geográfico desde donde emergen las raíces del principio material de la vida, sobre la base del ámbito ecológico, pasando por la mediación económica, para llegar a su consagración cultural (Dussel, 2006, 73). Por tanto, la idea de cultura surge desde la razón práctico-material ligada inicialmente con la sustentabilidad ecológica de la afirmación comunitaria, para remitir, desde esta condición basal, las formas de vivir en común, es decir, la cultura en tanto vivir político. Así se puede definir la cultura como un "conjunto orgánico de comportamientos predeterminados por actitudes ante los instrumentos de civilización, cuyo contenido teleológico está constituido por valores y símbolos del grupo, es decir, estilos de vida que se manifiestan en obras de cultura y que transforma el ámbito físico-animal en un 'mundo', un mundo cultural" (2015a,103).

La incidencia del espacio en la obra de Dussel es decisiva. Ejemplo de esto es la categoría de proximidad proveniente del núcleo ético-mítico semita cristalizada en el desierto arábigo $(2014 b, 6)$, sin embargo, igualmente adopta fisonomías concretas, por ejemplo, en la experiencia argentina y americana. Aquí Dussel advierte sobre la consternación experimentada por el conquistador, el criollo o el inmigrante en referencia a la vastedad del espacio argentino y su dimensión de infinito, olvido e impersonalidad. En contraposición a este "espacio vacío" 
para el horizonte de comprensión moderno-occidental, existe el enfoque epistémico del mundo indígena, para el cual "cada riachuelo, cada montaña o quebrada tenía nombre y era lugar de un huaca: era un espacio con significación" (2015a, 134). En cambio, los herederos del patrimonio epistémico occidental, esto es, los hijos de inmigrantes les han "puesto nombre a esos 'accidentes geográficos', y en vez de ser parte de un 'mundo' es sólo una "cosa" extraña. Extranjeros y como perdidos en nuestra tierra, "tierra geométrica, abstracta y como vacía" (134). Según esta arquitectónica, la concepción desarrollada por Dussel se asocia a la experiencia interior comunitaria, a la intersubjetividad configurada desde la corporalidad viviente. Desde este marco categorial, la cultura se comprende "sólo cuando nos incorporamos a la comunidad que la vive (...) lo que acaece es un vivir desde adentro que se aprende por tradición" (156). Este "vivir desde adentro", vinculado con la experiencia interior comunitaria, se articula basalmente, como veremos, con la dimensión mesiánica. La intersubjetividad radica en un lugar específico, en un espacio aesthesico claramente delimitado como es a nivel del сиегро (166).

Para Kusch la cultura está seminalmente arraigada al espacio, en lo que denomina geocultura (2000f, 247). Por tanto, más que el vivir político dusseliano, en Kusch se observa una suerte de política para vivir. Desde aquí se comprende la razón profunda de ser de cualquier cultura, como es "poder brindar a su integrante un horizonte simbólico que me posibilita la realización de mi proyecto existencial" $(2000 \mathrm{~g}, 612)$. Este horizonte simbólico es el que exhorta a no considerar nunca lo "americano" como cosa, pues es más bien la consecuencia "de una profunda decisión por lo americano entendido como un despiadado aquí y ahora y, por ende, como un enfrentamiento absoluto consigo mismo. La cultura americana es ante todo un modo: el modo de sacrificarse por América" (Kusch, 2000f, 105). Este despiadado aquí y ahora es el que atraviesa la experiencia del estar, la circunstancialidad de todo proyecto de existencia o modo de ser. Es, por tanto, el nivel máximo de referencialidad vital, corporal, desde donde todo "sacrificio por América" cobra sentido y desde donde las raíces del fundamento político de liberación pueden acuñar su verdadera dimensión. La cultura es política en la medida en que "es una estrategia para vivir en un lugar y en un tiempo" (Kusch, 2000f, 156), llevando a cabo las posibilidades de movilizar un ethos o forma de comportamiento sociocultural. De aquí que "ha de ser político en su sentido profundo como algo que consiste en despertar un ethos" (156). En el caso del núcleo ético-mítico amerindio, la noción de cultura surge "de una indigencia del existir mismo, en tanto requiere una forma de encontrar sentido en el existir" (156). Por tanto, supone "un suelo en el que obligadamente se habita, y habitar un lugar significa que no puede 
ser indiferente ante lo que aquí ocurre" (171). Desde este horizonte de referencialidad aesthesico-afectiva comunitaria, la situacionalidad, el lugar y la geocultura, son los principales "remedios" para descolonizar/liberar la indiferencia/anestesia presente en la generación de la "poiética moderna" (Soazo, 2019), en tanto poética narcótica/farmacológica ensimismada ${ }^{10}$.

La noción de pueblo se corresponde, según Dussel, con la "comunidad de vida", de acuerdo con el universo simbólico-material de cada cultura, lo que, siguiendo a Ricoeur, designa como núcleo ético-mítico (Dussel, 2015a, 100). Sin embargo, el uso político de la noción de pueblo trasciende a la comunidad política, estableciendo en ella una frontera interna. De aquí que plebs es una parte o "resto" de la comunidad que "tiende sin embargo a englobar a todos los ciudadanos (populus) en un nuevo orden futuro donde las actuales reivindicaciones serán satisfechas y alcanzarán una igualdad gracias a una lucha solidaria por los excluidos" (Dussel, 2006, 91). La temática crucial del consenso crítico del pueblo emerge y desaparece de acuerdo con las coyunturas, con la circunstancialidad constituyente de la génesis de lo político. Es por esto por lo que el pueblo como actor colectivo no puede concebirse como una forma sustantiva (esencialista) ni metafísica, sino sólo como un modo coyuntural - un emerger mesiánico como resto - como un "bloque" o un nuevo poder que está "debajo" y es cohesionado por su condición de resto insubsumible, por su densidad aesthesica ancestral. En este sentido: “cuando más participación hay de los miembros singulares en la comunidad de vida, cuando más se cumplen las reivindicaciones particulares y comunes, por convicción razonada, el poder de la comunidad, el poder del pueblo se transforma en una muralla que protege y en un motor que produce e innova" (Dussel, 2006, 25). En el caso de la obra de Kusch, la noción de comunidad se halla enraizada con el horizonte cultural indígena-popular, a partir de lo que este autor concibe como paquete ético-mítico $(2000 \mathrm{e}, 395)^{11}$. El ethos raigal de una cultura se encuentra totalmente informado por el horizonte simbólico, que es "ese lugar donde se da lo que se suele llamar cultura. La cultura encuadra el horizonte simbólico, y éste es el fundamento del existir mismo" (Kusch, 2000g, 165). Este encuadramiento provisiona los marcos categoriales mediante los cuales se organiza la experiencia de lo "real/natural", configurando el horizonte simbólico como el fundamento del existir mismo. No es algo derivado en el plano de una superestructura, sino un sustrato arquetípico vinculado con la experiencia circunstancial del estar. A partir de estas premisas, la idea de tecnificar u occidentalizar a América,

\footnotetext{
${ }^{10}$ Ligada categorialmente con las nociones de razón indolente y pensamiento ortopédico desarrolladas por Santos (2014, 439).

${ }^{11}$ En clara consonancia con los núcleos ético-míticos de una cultura desarrollados por Ricoeur (Dussel, 2015a: 100).
} 
incorporando el elemento de "civilización/transmisión” y prescindiendo del flujo vital del orden “cultura/comunicación" (Dussel, 2015a, 155), llevaría a adulterar superficialmente, como sostiene Kusch, "nuestra genuina voluntad de vivir por el simple hecho de que invierte la fórmula del estar para ser en otra de ser para estar" (2000g, 658). Esta inversión no es más que una fetichización ontológica y aesthesica del mundo moderno-occidental, en concordancia con su emplazamiento colonialista en territorio americano, cuyo horizonte de supremacía está determinado por el ser para estar, esto es, las formas de dominación/colonización, basadas en la ocupación del espacio, el nomos de la tierra, la idea de América como tabula rasa. A contrapelo se halla el estar para ser (estar-siendo), es decir, el horizonte transontológico o ético desde donde emerge la praxis de liberación.

Como se mencionó, en relación con el vínculo del don y la gratuidad, la proximidad es una categoría axial en el pensamiento de Dussel, dentro de un horizonte transontológico y transaesthesico comunitario. Es la disposición aesthesico-afectiva arquetípica, pues es "anterioridad anterior a toda anterioridad" $(2011,45)$. En efecto, es lo precedente al mundo, lo vinculado con el orden cosmológico, con la dimensión "realidad/naturaleza". Sin embargo, en la medida en que se nace en un mundo cultural, inmediatamente la proximidad deja lugar a la lejanía, al origen del poblamiento del mundo de entes ("patio de los objetos" según Kusch). Aunque este escenario sea el dominante en la cultura moderno-occidental, de igual modo se puede contravenir esa "lejanía", disminuyendo las distancias. Este "acortamiento" es el ejercicio de la praxis, es decir: "un obrar hacia el otro como otro; es una acción o actualidad que se dirige a la proximidad. La praxis es esto y nada más: un aproximarse a la proximidad" (2011: 46). Por su parte, la proxemia es un dirigirse a las cosas (46). De aquí que Dussel enfatice en la relación de inmediatez madre/hijo-hija, pues en este ámbito "se vive también como relación cultura-pueblo (totalidad simbólica)" (47). Desde este horizonte categorial eminentemente crítico se comprende que "anterior al mundo está el pueblo; anterior al ser está la realidad del otro; anterior a toda anterioridad está la responsabilidad por el débil” (47). Junto con su íntima vinculación con las nociones de don y gratuidad, la categoría de proximidad se articula directamente con la de reciprocidad, siendo ambas mutuamente constitutivas. En este sentido es que "acontece la reciprocidad originaria de la proximidad" (Dussel, 2011, 48). La proximidad fundada en la reciprocidad, y ligada fetichistamente con el mundo de la proxemia, se acerca cada vez más a lo que se puede llamar las "mediaciones de la distancia", o sea, las intervenciones de lo aesthesico o del espacio "vacío" e instrumental moderno-occidental, profesadas desde el mundo de las cosas, tendientes, según el horizonte epistémico moderno, a 
la acumulación, amplificación y fetichismo de todas las relaciones alterológicas, sustentadas desde el horizonte de proximidad comunitaria. En definitiva, la categoría de proximidad se vincula íntimamente con la reciprocidad, con la praxis y con una especie de aesthesis vida/muerte fundada sobre la sensibilidad y racionalidad vida/muerte. En contraposición, la proxemia se asocia, en el preciso contexto instrumental impuesto desde el sistema mundo moderno/colonial, con la amplificación simbólica y aesthesica del mundo, con la acumulación incitada por la cultura capitalista y por el fetichismo de los objetos, de su poiesis, en lo que se puede denominar una "poiética de la modernidad" 12.

En el pensamiento de Kusch, la condición análoga a la categoría de proximidad dusseliana, en referencia a su fundamentación comunitaria, es la figura del estar reunidos. En esta noción se observa cómo el aquí de la presión de lo absoluto, es decir, la imposición de la realidad/naturaleza, del orden cosmológico, es una experiencia aesthesica comunitaria. En este sentido, no es una vivencia del uno mismo en soledad, sino un modo ritual de ver y por eso es de todos: "de ahí que la comunidad no sea lo que todos mantienen en común, sino que es, esencialmente, un constante estar reunidos, o sea la ecclesia en su sentido elemental, o sea la reunión para encontrar a través del diálogo el verbo que brinde el sentido" (Kusch, 2000e, 366). Se subraya en este pasaje que más que ser "lo común" lo predominante de la comunidad, en tanto "contenido" determinado, ya sea de una "esencia metafísica" o de un "orden objetual", lo fundamental de la idea de comunidad es el "estar reunidos" referido precisamente con la categoría de proximidad, contacto, religación, dimensión ritualística y raigalidad del verbo estar. Se juega aquí, por tanto, la fuerza aesthesica comunitaria involucrada en volver a la unión (implicando las fuerzas políticas de la unión, de las grandes mayorías); a la unidad, a la comunidad, a la proximidad histórica, en suma, siguiendo a Dussel, a la referencialidad primera u origen de toda significación $(2011,45)$ que, para Kusch, remite a lo indeterminable e inefable de la experiencia del estar, del devenir o de la alteridad yaciente en el seno de la comunidad. De aquí que, para este autor, dentro del contexto del mundo occidental, el arte moderno encarne la búsqueda de esa ecclesia original, utópica, vinculada supuestamente, para la imaginería eurocéntrica, con el mundo "no-moderno", por tanto, con un "horizonte perdido", situado en el pasado primitivo de la línea temporal del historicismo moderno.

A partir de la consideración de una geocultura como horizonte simbólico-material originario e igualmente de las categorías fundacionales de comunidad y pueblo, se comprende la significación de la noción de mesianismo en el contexto del paradigma de la liberación

\footnotetext{
${ }^{12}$ Para las categorías de aesthesis vida/muerte y poiética de la modernidad, cf. Soazo (2019).
} 
latinoamericano. Su primera condición, como lo expone Dussel, es confrontar todas las energías aesthesicas del fetichismo presentes tanto en el orden de los objetos, por ejemplo, a nivel de la acumulación capitalista y la fetichización de la mercancía, como asimismo a nivel ideológico, en el ámbito de la voluntad de poder (Nietzsche), la hybris del punto cero (Castro-Gómez), el pensamiento abismal moderno-occidental (Santos), en suma, en la superioridad del "centro" metropolitano por sobre la periferia global. Frente a toda imagen fetichista y práctica corrupta, se activa la función mesiánica en tanto energía aesthesica comunitaria insubsumible y por tanto incorruptible frente al poder estético dominante. Dussel sostiene al respecto que el meshiakh es "el maestro incorruptible que es tal, porque aunque tenga miedo como todo ser humano a la muerte no duda cuando debe inmolarla en favor de la vida, y en primer lugar de la vida del pueblo, de los oprimido, de los excluidos" (2014b, 170). Es, asimismo, "el fundador, singular o colectivo, en el tiempo del kairós: el tiempo del extremo peligro, el 'tiempo que queda' ante la muerte, como si la vida cotidiana se hubiera terminado para siempre" (170). Se dispone aquí del tiempo de la referencia, o de lo referencial mismo, esto es, el tiempo de la aesthesis vida/muerte, del valor de uso comunitario fundacional, su reproducción social originaria. En este escenario conceptual se concibe el servicio opuesto al fetichismo, orientado sobre la praxis, sobre el uso (Agamben, 2017). Desde aquí se relaciona con la política, con la redención de lo viviente, de los sojuzgados, humillados y excluidos, con una forma primigenia de liberación. Esta forma aesthesica de liberación es una creación colectiva del pueblo, conforme a que la creación de un pueblo como tal, en tanto "pueblo", es su liberación (177). De acuerdo con este marco categorial, la hiperpotencia o estado de rebeldía se manifiesta cuando "las víctimas del sistema político vigente no-pueden-vivir plenamente (por ello son víctimas). Su voluntad-devivir ha sido negada por la voluntad-de-poder de los poderosos” (Dussel, 2006, 94). Lo popular se constituye en la última referencia y reserva regenerativa de hiperpotencia, pues es lo propio del pueblo en sentido estricto, esto es, ligado con el "bloque social de los oprimidos" (92). Es un universo aesthesico-afectivo que permanece debajo de todos los procesos modernizantes, especialmente cuando en el horizonte cultural existe una gran influencia de "pueblos indígenas" $(92)^{13}$. La hiperpotencia es el nuevo poder de los de "abajo", expresión de una fuerza o energía invencible que "quiere-vivir"; ser expresión sensible de una "voluntad-de-vida" (112).

Para Kusch, la actitud mesiánica también se encuentra relacionada con las nociones de salvación e ira divina $(2000$ b , 18), en la medida en que lo que está en juego en el ethos indígena,

\footnotetext{
${ }^{13}$ Dussel sostiene que, en el caso de los pueblos mayas, aymaras y quechuas, entre muchos otros, su ethos cultural irá más allá de la modernidad: "en la civilización transcapitalista, trans-moderna, no pos-moderna que todavía es moderna, eurocéntrica, metropolitana” $(2006,92)$.
} 
más allá del causalismo logocéntrico objetual, es la salvación “interior/común” alojada en la referencialidad de la vida, en la corporalidad viviente - ligada tanto al individuo como a la comunidad - frente a la muerte, ante las fuerzas intempestivas e indimensionables de la "realidad/naturaleza". Esta conceptualización es la que sustenta la metáfora propuesta por Kusch como "ira divina”. La actitud mesiánica se encuentra aquí situada "sólo hacia el interior de América, remontando su pasado o bajando hacia las capas más profundas de su pueblo. Arriba, en cambio, aquella actitud se halla encubierta y reprimida" (2000b, 18). Entonces, se presentan dos grupos como si fueran antagónicos: "por una parte, los estratos profundos de América con su raíz mesiánica y su ira divina a flor de piel y, por otra, los progresistas y occidentalizados ciudadanos" (18). La problemática sobre la experiencia mesiánica gira en torno a la presencia de la ira divina o las fuerzas "irracionales" de la naturaleza que atraviesan el corazón de la comunidad. Aquélla sólo puede ser ley u orden en la medida en que su fin sea "preservar la vida humana frente al caos, pero sin eliminarlo" (Kusch, 2000b, 199). El quid de la cuestión es que el pueblo, los sujetos pertenecientes al horizonte cultural indígena-popular, no puede ser modelado técnicamente. Se encuentra completamente interconectado, arraigado intersubjetivamente, por todo su sistema sociocultural, su horizonte histórico-comunitario, con las fuerzas cosmológicas de la ira divina, con el universo referencial o espacio aesthesico arquetípico de la vida y la muerte. Por tanto, existe en ellos una facultad o potencia inaudita que "se manifiesta súbitamente para dar todo de sí mismo" (Kusch, 2000f, 247). Esta vivencia de manifestarse súbitamente corresponde con la noción de hiperpotencia desarrollada por Dussel, es decir, con el poder emergente desde abajo, desde los oprimidos y excluidos de la historia que, en cualquier coyuntura histórica significativa, irrumpen repentinamente, muchas veces más allá de lo presupuestado por sus mismos protagonistas. La experiencia mesiánica se relaciona asimismo con la "violencia divina" de Benjamin, es decir, la violencia en favor de la vida y liberadora de la culpa generada por la ley $(1991,38)$. La figura del mesianismo apunta entonces al despliegue de las fuerzas naturales, en tanto activación/presentización del plano "realidad/naturaleza", aunque siempre inscrito aesthesicamente en la cultura, en el mundo (Dussel, 2011). Es desde aquí, entonces, desde donde se recoge la energía psicoafectiva/psicofísica, presente privilegiadamente en la experiencia religiosa, como muy bien lo sabía Mariátegui en el contexto latinoamericano, vinculándola con los fundamentos de la experiencia genuinamente revolucionaria fundamentada por la función mesiánica. Ésta no es la simple espera del "mero estar" o el advenimiento de alguna acción exógena, como lo expresa la concepción convencional del mesianismo. Por el hecho de ser un marco categorial monista, 
en el que es inconcebible una escisión entre el orden de la acción y la pasión, la disposición predominante aquí es la participación unida a la lógica de la presencia/pertenencia, instalada desde los basamentos del mundo ritual y mítico de la cultura. Aquí la "ira divina" es una expresión ritual/cultual propia del núcleo ético-mítico de los pueblos andinos, totalmente "semejante" con el plano material económico-ecológico, por ejemplo, en los cultos/trabajos en torno a las cosechas, a la presencia del maíz o la maleza, de la vida o la muerte.

Finalmente, una nueva estética para Dussel, como se ha argumentado en este trabajo, necesariamente tiene que ser comunitaria. Cuando el pueblo se expresa, el "genio" artístico moderno es descolonizado, revelando así su condición, en primer término, de "artesano", y no de una "excepcionalidad/marginalidad" con que la estética moderna tiñó el aura "fascinante" del genio (Bourdieu, 1995). A contrapelo de esta caracterización, el "artesano", en tanto obrero de la techne, del "saber hacer" conforme a reglas (poitike episteme o techne), es un mero "servidor" que celebra la percepción estética de la comunidad. Las obras de arte que produce nutren "a la comunidad para vitalizar (como hiperpotentia aesthetica) el patriotismo en estado de rebelión, la aspiración hacia la liberación" (Dussel, 2018, 33). El "genio" pierde el aura de excepción y singularidad incontrarrestable del sujeto moderno, y al igual que la categoría de "resto" en la política, puede ser "uno que es a la vez todos", es decir, la comunidad: un nosotros interpelante de lo común, de la proximidad/reciprocidad originaria, pues nace del presupuesto de una estética comunitaria, siendo a su vez su consagración. El pueblo es la potencia aesthesica, la sede ontológica de la aesthesis y el actor protagónico de su puesta en obra (Dussel, 2018, 33). La modernidad determina el sistema vigente estético-hegemónico, afirmándose sobre el no-ser, la exterioridad, el otro. Afirmación por negación, anulación o necropoiética. Este no-ser comienza a tomar conciencia de sí mismo, despertando su subjetividad mesiánica ante el estado de abuso e injusticia existente en el mundo. Se entra así en un estado de rebeldía, en el tiempo del peligro o de la referencialidad vital. Desde aquí emerge una nueva experiencia de la aesthesis, superando el fetichismo de la belleza moderna, mediante la acción mesiánica. Así la estética de la liberación es una estética futura pluriversal, respetuosa de las distinciones analógicas, que dan cuenta de que "otra estética es posible" (Dussel, 2018, 34), esto es, la expresión sensible de otro marco categorial como el del lema zapatista.

En el pensamiento de Kusch, el análogo a una nueva estética es la creación de un nuevo arte ("gran arte") igualmente centrado en torno a la dimensión comunitaria de la experiencia humana. Desde este supuesto se desprende que Kusch conciba el arte occidental ante todo como 
"un arte de producción y no de creación ${ }^{14}$. De ahí que sea un arte con una estética del placer y de la forma (2000a, 782). En cambio, en la experiencia del tango, éste espejea "la absoluta frustración frente a la adquisición de las cosas de la ciudad. De ahí que su significado sea el de una célula estética de simple perduración y sobrevivencia” (811). Existe aquí una tristeza sin parangón en un mundo ya reificado por las relaciones proxémicas o funcionales sujeto-objeto (donde radica precisamente la fetichización de lo humano). Esta idea se aprecia en una serie de manifestaciones del baile, como, por ejemplo, “en el esbozo del gesto, la concentración, el hierático trazo de los pasos que orlan con un garabato mágico la vida en el piso" (811). Existe aquí el boceto de una actitud íntegra, basada en relaciones de proximidad, sujeto-sujeto, de orden alterológica, que no logra resolverse en el mundo dispuesto por la ciudad (811). En contraposición a este universo de sentido, lo indígena no se vincula ya con el mundo de las soluciones científicas, sino con el ámbito de la salvación/conjuración, donde la "espera/acción" es el horizonte en el que se juega la vida o la muerte: la circunstancia política radical y la instalación aesthesica arquetípica. Este escenario no representa ya sólo una solución estética, sino también sociológica, e incluso más, de orden antropológico-cultural, dado que "para nuestro existir ciudadano en América, puesto que roza una involución de lo humano hacia el fondo nutritivo, una especie de reestructuración de los componentes universales de la cultura humana en función de otro criterio" (Kusch, 2000a, 800). En el "gran arte”, por ejemplo, se actualizan antiguos planteos vitales, los cuales pueden ser reestructuraciones descolonizadoras, destacando aquello socialmente excluido o relegado como algo tenebroso frente a la inteligencia social (783). El gran arte americano debiese emerger de la liberación de lo tenebroso, lo social/racialmente excluido o relegado por el canon formal-social occidental. Así, la supuesta “ausencia” de un gran arte en América se debe, según Kusch, a que no se da el acto estético, ya que existe una coartación del hecho estético. Las obras de arte, colonizadas y eurocéntricas, suplantando un plano óntico, vinculado con el mundo de la poiesis (relaciones sujeto-objeto) y de la proxemia instrumental, por sobre un universo ético o transontológico, fundado sobre la base del horizonte de la praxis (relaciones sujeto-sujeto), de la proximidad comunitaria, se elaboran directamente en el plano formal de la techne, careciendo de la vitalidad real de la corporalidad humana (784). Esta energía real es la que subyace a una nueva experiencia aesthesica o estética comunitaria y que, por el hecho de ser real, no hay una forma para ella, como no hay - aparentemente - forma para lo gauchesco o lo indio (784), es decir, para todas

\footnotetext{
${ }^{14}$ Donde la producción en este caso remite a "proxemia", al mundo del "ser", como la creación a "proximidad", a la experiencia del "estar".
} 
las exterioridades del sistema. Se parte normalmente de una vivencia elaborada o adquirida para arribar a una forma rigurosamente preestablecida, una suerte de aesthesis de la ficción que es el nudo gordiano de la dominadora "poiética moderna" del sistema mundo moderno/colonial. Sin embargo, la aesthesis vida/muerte es una pulsión seminal nunca anestesiable del todo, pues es la misma energía vital puesta en obra a través de la praxis de liberación, es decir, en torno a la proximidad histórica o a la aesthesis descolonial comunitaria.

\section{REFERENCIAS}

Agamben, Giorgio (2017). El uso de los cuerpos. Buenos Aires: Adriana Hidalgo Editora.

Benjamin, Walter (1991). Para una crítica de la violencia en: Para una crítica de la violencia y otros ensayos. Iluminaciones IV. México: Taurus.

Bourdieu, Pierre (1995). Las reglas del arte. Barcelona: Anagrama.

Dussel, Enrique (1974). Método para una filosofía de la liberación. Salamanca: Ediciones Sígueme.

Dussel, Enrique (1984). Filosofia de la producción. Bogotá: Editorial Nueva América.

Dussel, Enrique (2006). 20 tesis de política. México: Siglo XXI editores.

Dussel, Enrique (2011). Filosofía de la liberación. México: Fondo de Cultura Económica.

Dussel, Enrique (2014a). 16 tesis de economía política. Una interpretación filosófica. México: Siglo XXI editores.

Dussel, Enrique (2014b). 14 tesis de ética. Madrid: Trotta.

Dussel, Enrique (2015a). Filosofía de la cultura y Trans-modernidad. México: Universidad autónoma de la Ciudad de México.

Dussel, Enrique (2015b). Filosofías del Sur. México: Akal.

Dussel, Enrique (2018). "Siete hipótesis para una estética de la liberación” en: Praxis. Revista de Filosofía Número 77, enero-junio.

Echeverría, Bolívar (2010). Modernidad y blanquitud. México: Ediciones Era.

Fanon, Frantz (2009). Piel negra, máscaras blancas. Madrid: Editorial Akal.

Hinkelammert, Franz (2017). La vida o el capital: El grito del sujeto vivo y corporal frente a la ley del mercado (antología esencial). Buenos Aires: CLACSO/ALAS.

Kusch, Rodolfo (2000a). Anotaciones para un arte americano en: Obras completas tomo IV. Córdoba Argentina: Editorial Fundación Ross.

Kusch, Rodolfo (2000b). América profunda en: Obras completas tomo II. Rosario Argentina: Editorial Fundación Ross. 
Kusch, Rodolfo (2000c). El pensamiento indígena y popular en América en: Obras completas tomo II. Córdoba Argentina: Editorial Fundación Ross.

Kusch, Rodolfo (2000d). Indios, porteños y dioses en: Obras completas tomo I. Córdoba Argentina: Editorial Fundación Ross.

Kusch, Rodolfo (2000e). Esbozo de una antropología filosófica americana en: Obras completas tomo III. Córdoba Argentina: Editorial Fundación Ross.

Kusch, Rodolfo (2000f). Geocultura del hombre americano en: Obras completas tomo III. Córdoba Argentina: Editorial Fundación Ross.

Kusch, Rodolfo (2000g). La negación en el pensamiento popular en: Obras completas tomo II. Córdoba Argentina: Editorial Fundación Ross.

Kusch, Rodolfo (2000h). El sentido de lo trágico en el teatro indígena en: Obras completas tomo IV. Córdoba Argentina: Editorial Fundación Ross.

Santos, Boaventura de Sousa (2013). Descolonizar el saber, reinventar el poder. Santiago: Lom.

Santos, Boaventura de Sousa y Meneses, María Paula (eds) (2014). Epistemologías del Sur (perspectivas). Madrid: Akal.

Soazo, Christian (2018). "Espacio colonial y aesthesis soberana: praxis decolonial desde la experiencia vivida del negro según Fanon”. Revista Pléyade, 21, enero-junio, pp. 93-117.

Soazo, Christian (2019). "Giro afectivo decolonial: De la culpa/deuda moderna a la dignidad de lo viviente. Reflexiones desde un enfoque analéctico". Revista Nuestramérica. Vol 7, N 13 , enero-junio. 